\title{
Solar Thermal Power Generation and Its Application
}

\author{
Guozhu Weng \\ Department of Power Engineering, North China Electric Power University, Baoding, China
}

Keywords: solar thermal power generation, characteristics, application, trends.

\begin{abstract}
Solar thermal power generation has a bright future globally. This paper describes the main forms and characteristics of solar thermal power generation, introduces the application of solar energy at home and abroad, analyzes its development trends, and puts forward suggestions for improvement and the current research direction.
\end{abstract}

\section{Introduction}

With the advancement of industrialization and the improvement of people's living standard, the global energy demand is increasing dramatically. The traditional chemical energy reserves are limited, so it is difficult to meet the growing demand for energy nowadays. And excessive use of chemical energy will have a negative impact on the environment, causing a series of problems such as greenhouse effect and ecological imbalance. In order to cope with the current energy crisis, people are becoming more and more aware of the need to develop new energy sources, improve the energy utilization technology, and gradually replace the traditional energy sources. Solar energy, as a renewable and clean energy, has broad prospects for development, and has been widely concerned by people. This paper describes the main forms and characteristics of solar thermal power generation, introduces the use of solar energy at home and abroad, analyzes its development trends, and puts forward suggestions for improvement and the current research direction.

\section{The Main Forms and Characteristics}

\subsection{The Main Forms of Solar Thermal Power Generation}

Solar thermal power generation is a technology, which uses massive arrays of parabolic or dish shaped mirrors to collect the sun's heat and to generate steam through the heat exchanger, combined with the technology of traditional turbo-generator to generate electricity. In a variety of renewable energy, solar thermal power generation has the characteristics of high generating efficiency, low cost of power generation, good power quality, and large-scale heat storage. Relative to extremely unstable wind power and photovoltaic power generation, which abandon wind or light frequently, it has unmatched advantages [1].

Solar thermal power generation exist in three common forms, namely parabolic trough, dishengine, and solar power tower. After linear discretization, parabolic trough is transformed into concentrating linear Fresnel reflector. Wherein parabolic trough and concentrating linear Fresnel reflector adopt line-focusing, while dish-engine and solar power tower adopt spot-focusing. Four types of solar thermal power generation are shown in figure 1. 


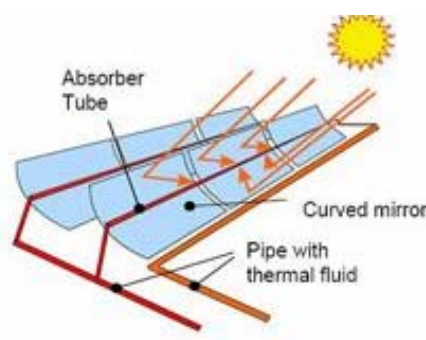

Parabolic Trough

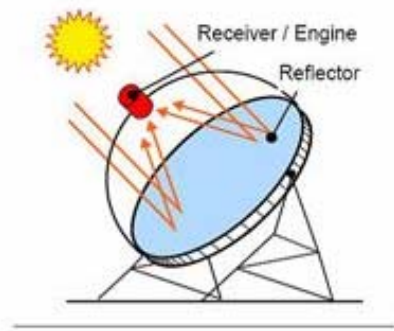

Dish/Engine

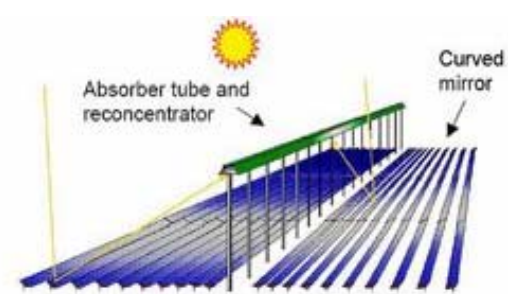

Linear Fresnel

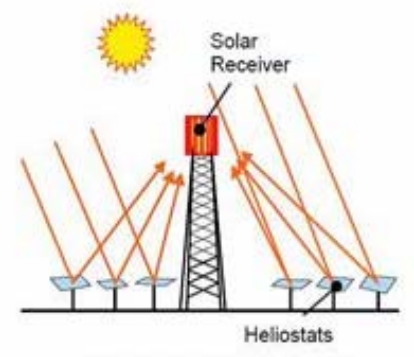

Central Receiver

Fig. 1 Four types of solar thermal power generation

\subsection{The Characteristics of Solar Thermal Power Generation}

With high concentration ratio, solar power tower operates at extremely high temperature up to more than 1300 DEG C, and therefore it has rather high heat conversion efficiency, combined with heat storage system and stores energy in high temperature, to achieve a smooth and controllable power output and to offer a basic load of power.

Although the solar power tower can output high quality power, with complex tracking systems its initial investment and operating costs is high and it will take up large area. As technology improves, it may significantly reduce costs, and can achieve large-scale applications, so solar power tower is the future direction of development.

Parabolic trough solar power is relatively mature and its system is simpler, and consequently it is the first to enter the commercial production of solar thermal power generation with low cost. However, its operating temperature and photo-thermal conversion efficiency are low, the parameters are limited. The fact that it is difficult to work in the wind area with poor wind resistant performance is also a factor limiting parabolic trough solar power's development. Furthermore, serious heat loss for its long receiver and large radiating area is also a problem.

Dish-engine adopts spot-focusing, and it has a lot of advantages such as high photo-thermal conversion efficiency, distributed arranged heat collectors, low operating cost and so on. A single machine produced standardly, not only can be used for a separate power supply as a distributed system but also be used for the grid. Unfortunately, its receiver is complex and expensive, which makes single scale is difficult to expand, so the generation cost is also relatively high.

Concentrating linear Fresnel reflector with simple structure, has the advantages of low cost of power generation and better wind-resistant performance, but its work efficiency is low. Because of the short development history, related technology is not yet mature, linear Fresnel reflector still in the stage of demonstration project [2].

\section{Current Situations of Solar Thermal Power Generation at Home and Abroad}

\subsection{Current Situation of Solar Thermal Power Generation at Home}

The research and development of solar thermal power generation in China started in the late 70s. Some universities, research institutes and other units and institutions have done a lot of practical basic experimental research on solar thermal power generation technology. Under the guidance of the Ministry of science and technology, 19 enterprises, 8 research institutes and 19 universities jointly established a strategic alliance of solar energy and light industry technology innovation [3].

In 1978, the Chinese Academy of Sciences established the solar thermal power measurement and control laboratory, and later research can be broadly divided into three stages. The first stage is the 
period from "The Eighth Five-Year Plan" to "The Ninth Five-Year Plan", when the state supported scientific research units to develop trough solar concentrators.

The second stage is the "Tenth Five-Year Plan" period, when $1 \mathrm{~kW}$ disc-type Stirling power generation system was successfully developed relying on the "863 plan". In 2005, a 70kW tower power generation system combined with solar energy and gas was established in Nanjing.

The third stage is the "Eleventh Five-Year Plan" period, China has increased the research on solar thermal power generation, and in 2006 launched the "863" key project "solar thermal power generation technology and system demonstration". The $1 \mathrm{~kW}$ dish Stirlings solar thermal power generation system was established in 2006 by the Institute of electronics, Chinese Academy of sciences. In the conditions of direct radiation intensity greater than $450 \mathrm{~W} / \mathrm{m}^{2}$, the system successfully completed a stable continuous output line voltage of $100 \mathrm{~V}$ or so three-phase AC test, becoming the first continuous power generation of the dish Stirlings solar thermal power generation system. In addition, the "973" key project "efficient large-scale solar thermal power technology basic research" was launched in 2009 [4].

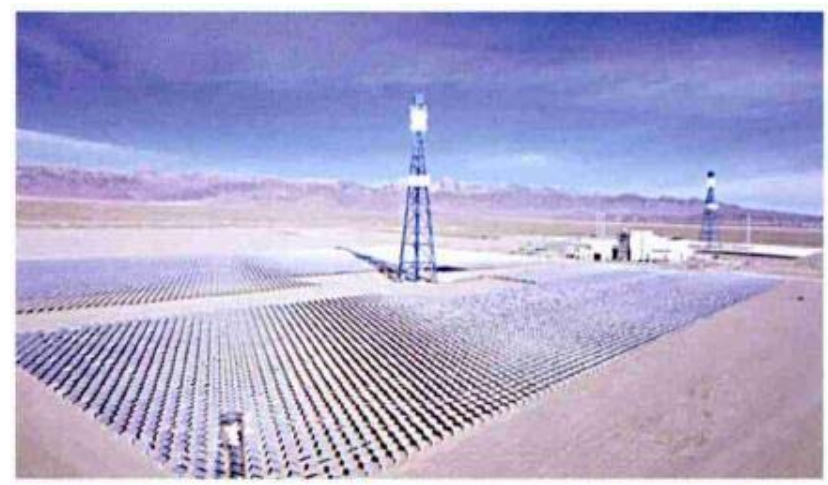

Fig. 2 the first phase of the 50MW tower solar power station in Delingha, Qinghai Province

During the "12th Five-Year" period, solar thermal power generation developed explosively. In 2010, the Chinese Academy of Sciences, Himin solar energy and Huadian Group jointly built 1MW tower solar thermal power stations in Badaling, Beijing. The power station in August 2012 successfully generated electricity, and it is the megawatt tower solar power station by China's own research, development, design and construction. It has a condenser tower with $100 \mathrm{~m}$ height, 100 surface heliostats, and the fluid work at $390^{\circ} \mathrm{C}$ and $2.35 \mathrm{MPa}$. In 2012, a 50MW tower solar power plant project in Delingha, Qinghai Province. A power generation capacity of 10MW, divided into two 5MW concentrating mirror fields, each corresponding to a collector tower, the tower total height of about 92m. The first tower was put into operation in August 2012, and second towers were put into operation in December 2012, as shown in figure 2. In addition, China Guangdong Nuclear Power started 50MW trough solar thermal power generation project in Qinghai Delingha in 2012, covering an area of 246 hectares, with a total investment of 2.5 billion yuan, the annual generating capacity of 200 million KW/h. It can achieve solar 24-hour power generation, power stability close to thermal power.

\subsection{Current Situation of Solar Thermal Power Generation Abroad}

At present, Spain, the United States, North Africa and the Middle East have a large number of solar thermal power stations built or under construction. As of May 2010, the world has been put into the grid to run the solar thermal power installed capacity of 736MW, the construction of the project installed capacity of 2080MW, and has signed a power purchase agreement of the project installed capacity of 17566MW [5].

Currently, the world's largest commercial solar thermal tower power station is the Spanish PS10, with an installed capacity of 11MWe, while the largest solar thermal tower power plant under construction is the Spanish PS20 with an installed capacity of 20MWe. 


\section{Prospects and Trends}

\subsection{Prospects of Solar Thermal Power Generation}

Solar energy is clean energy, using solar energy to generate electricity without pollution. In the future, clean energy must be the mainstream, and solar thermal power generation is in line with the trend. Solar energy is inexhaustible. The energy of the sun shining on the earth per second is equivalent to the energy contained in 5 million tons of coal. Calculated with 3\% of the world's desert (129.9 billion $\left.\mathrm{m}^{2}\right), 10000 \mathrm{GW}$ solar thermal power can be installed, which can supply $50 \%$ of the world's electricity demand.

\subsection{Trends of Solar Thermal Power Generation}

\subsubsection{High Parameters and High Efficiency}

At present, low efficiency and low parameters in solar power generation bring about high costs.High parameters can increase power generation and improve efficiency. For example, increasing the collector temperature can increase efficiency, as shown in figure 3. Therefore, the overall solar power will be in the direction of high parameters, high efficiency.

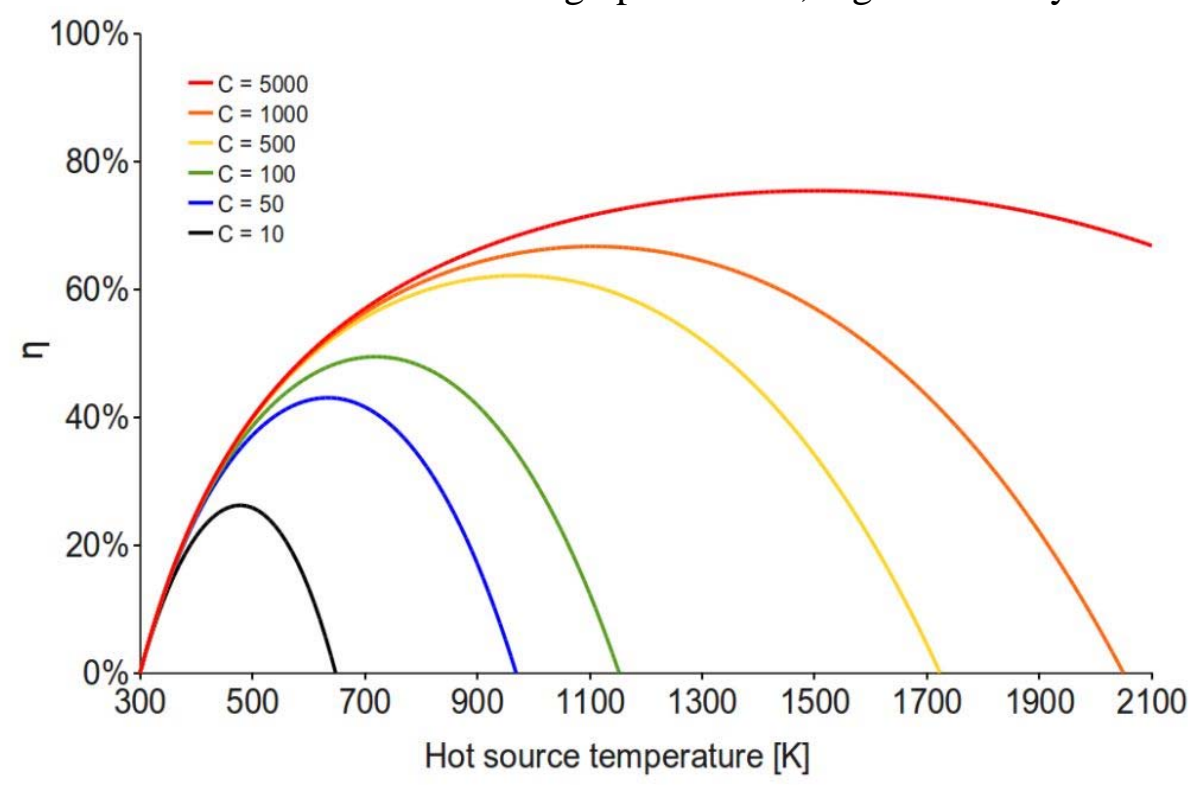

Fig. 3 Efficiency and collector temperature of solar thermal power generation system

\subsubsection{Give First Place to Solar Power Tower}

At present, solar power generation is mainly through type, accounting for about $87.9 \%$ of the total installed capacity.

Because the trough type power generation technology is most mature, and the risk is smallest, trough power generation is dominant at this stage. But in a more efficient future, a more efficient tower would dominate. The national "863" project "1MW tower solar thermal power generation demonstration project" focus on promoting research and development of the key technology in tower solar thermal power generation. It establishes experimental systems and platforms to explore largescale, low-cost commercial power plant technical approach.

Therefore, in the future form of solar power will be the main tower.

\section{Conclusion}

Solar thermal power generation, as a high efficiency, excellent quality and high stability power generation, has a very high prospects for development. Compared with other energy sources, solar energy is not exhausted, and is distributed all over the world. With the progress of technology, the cost of solar thermal power generation will gradually reduce, and the development of solar thermal power generation will be promoted. It is expected that by 2020, solar thermal power generation will enter the era of large-scale use globally. 


\section{References}

[1]. ZHOU Kai, YU Zhiyong, LI Xin, Status and Trend of Parabolic Trough Solar Power Technology [J]. Energy Research and Management, 2014, (04):17-22.

[2]. Liu Yalan, Wei Jiande, Zhang Yajuan, Development Status of Solar Thermal Power Generation Technology [J]. Enterprise Reform and Management, 2015, (07):117-118.

[3]. Zhao Zhihua, Liu Jianjun, Present Situation of Development and Application of Solar Thermal Power Generation Technology in China [J]. Solar Energy, 2013, (24):29-32.

[4]. ZENG Lecai, Application Prospects for Solar Thermal Power Generation and Technology Development Trend Analysis [J]. Journal of Shanghai Electric Technology, 2012, (04):53-58.

[5]. Yan Yunfei, Zhang Zhien, Zhang Li, Dai Changlin, Application and Utilization Technology of Solar Energy [J]. Acta Energiae Solaris Sinica, 2012, S1:47-48. 